\title{
As memórias discursivas que emergem do discurso do Projeto Pedagógico de um curso técnico vinculado ao Pronatec Campo no IFTO, Campus Araguatins-TO
}

\author{
Jorlan Lima Oliveira ${ }^{1}$ \\ ${ }^{1}$ Faculdade Integrada de Araguatins - FAIARA. Coordenação de Iniciação à Pesquisa e Extensão. Avenida Araguaia, 1105, \\ centro. Araguatins-TO. Brasil. \\ Autor para correspondência/Author for correspondence: jorlan.oliveira.jlo@gmail.com
}

RESUMO. A pesquisa tem como objetivo analisar os efeitos de sentido (memórias discursivas) que emergem do discurso do Projeto Pedagógico do Curso de Auxiliar Técnico em Agropecuária, ofertado pelo Instituto Federal do Tocantins, Campus Araguatins, entre os anos de 2013 e 2014, como parte integrante do Pronatec Campo. Tal curso de curta duração tinha como foco oferecer conhecimentos básicos - referentes às atividades agropecuárias - aos camponeses pertencentes aos assentamentos localizados no município de Araguatins-TO e proximidades. Foi utilizada como fundamentação metodológica a Análise de Discurso com base nos estudos de Pêcheux (1999), Achard (1999) e Orlandi (1999). A partir deste estudo, destacase que os enunciados remetem a memórias discursivas que evocam a formação tecnicista, além de vincular o exercício da cidadania à produtividade em um ambiente capitalista.

Palavras-chave: Pronatec Campo, Formação do Camponês, Políticas Públicas. 


\title{
The discursive memories that emerge from the discourse of the Pedagogical Project of a technical course linked to Pronatec Campo at the IFTO, Campus Araguatins-TO
}

\begin{abstract}
The aim of this research is to analyze the effects of meaning (discursive memories) that emerge from the discourse of the Pedagogical Project of the Technical Auxiliary Course in Agriculture, offered by the Federal Institute of Tocantins, Campus Araguatins between the years of 2013 and 2014, as part member of Pronatec Campo. This short course focused on providing basic knowledge regarding agricultural activities to peasants belonging to the settlements located in the municipality of Araguatins-TO and nearby Discourse Analysis was used as methodological foundation based on the studies of Pêcheux (1999) and Orlandi (1999). From the analysis it is highlighted that the statements refer to the discursive memories that evoke the technicist formation, in addition to linking the exercise of citizenship to productivity in a capitalist environment.
\end{abstract}

Keywords: Pronatec Countryside, Formation of the Peasant, Public Policies. 


\section{Las memorias discursivas que emergen del discurso del Proyecto Pedagógico de un curso técnico vinculado al Pronatec Campo en el IFTO, Campus Araguatins-To}

RESUMEN. La investigación tiene el objetivo de analizar los efectos de sentido (memorias discursivas) que emergen del discurso del Proyecto Pedagógico del Curso de Auxiliar Técnico en Agropecuaria, ofrecido por el Instituto Federal de Tocantins, Campus Araguatins entre los años 2013 y 2014, como parte y en el caso de las mujeres. Tal curso de corta duración tenía como foco ofrecer conocimientos básicos en cuanto a las actividades agropecuarias a los campesinos pertenecientes a los asentamientos ubicados en el municipio de Araguatins-TO y cercanías. Se utilizó como fundamentación metodológica el Análisis de Discurso basado en los estudios de Pêcheux (1999), Achard (1999) y Orlandi (1999). A partir del análisis se destaca que los enunciados remiten a memorias discursivas que evocan la formación tecnicista, además de vincular el ejercicio de la ciudadanía a la productividad en un ambiente capitalista.

Palabras clave: Pronatec Campo, Formación del Campesino, Políticas Públicas. 


\section{Introdução}

Este artigo é parte da dissertação de mestrado cujo tema principal é "PRONATEC e a Educação do Campo: a disputa de projetos no interior de uma política de formação do camponês ${ }^{\mathrm{i}}$ ". Este estudo tem como finalidade analisar os efeitos de sentido (memórias discursivas) que emergem no discurso do Projeto Pedagógico do Curso (PPC) de Auxiliar Técnico em Agropecuária elegido como corpus de análise deste trabalho.

A motivação desta pesquisa se deu a partir das vivências e inquietações levantadas durante a participação do pesquisador como professor do Programa Nacional de Ensino Técnico e Emprego (PRONATEC). Programa encampado pelo Instituto Federal e Tecnológico do Tocantins (IFTO), Campus de Araguatins, Estado do Tocantins, que ofereceu cursos profissionalizantes de curta duração para os camponeses em diversos assentamentos do município e cidades circunvizinhas. A experiência neste programa durou dois anos - entre 2013 e 2014 - e neste período foram ministradas as seguintes disciplinas: associativismo, cooperativismo e comercialização de produtos agropecuários.

Durante essa rotina educacional, vários assentamentos foram visitados, nesse percurso foi percebido que o discurso defendido - de formá-los tecnicamente para assim melhorar seus afazeres do campo - talvez não fosse a única maneira de fazer com que aqueles sujeitos pudessem ser protagonistas de sua história. Com o passar do tempo, foi observado que a realidade dos assentamentos não cabia na dinâmica do ensino profissional influenciado pelo mercado, ou seja, pode-se observar nos discursos dos sujeitos e na prática do cotidiano das aulas nos assentamentos a disputa de projetos educacionais que envolvem os movimentos sociais do campo e os que são inerentes da iniciativa capitalista.

Entende-se que esses projetos educacionais nascem sob forte influência política e ideológica e estas disputas ocorrem de diversas formas, inclusive podem ser evidenciadas na malha discursiva.

Este artigo tem na primeira seção uma discussão a respeito da influência dos novos ordenamentos produtivos que nasceram do regime de produção capitalista, denominado regime flexível e a noção de competência. Na segunda seção, apresentam-se as características do PRONATEC enquanto política pública de acesso à educação profissionalizante. Em seguida são abordados os aspectos 
metodológicos da pesquisa e, por fim, a análise de excertos do discurso do PPC.

\section{Regime de acumulação flexível: a "nova" estratégia do capital}

O regime de acumulação flexível surgiu como uma forma de adaptação do capitalismo em resposta à crise econômica, que sucedeu a partir da década de 1960 e pelas inovações tecnológicas e científicas que surgiram a partir desse período. Essa nova forma de atuação do capital exigiu transformações nas políticas educacionais de formação do trabalhador, com foco na preparação do sujeito para um mercado competitivo e de alta rotatividade de empregos. Nesse sentido, Kuenzer (2007) ressalta que esse processo de formação serviu para aprofundar a dualidade educacional ${ }^{\text {ii }}$ que de maneira intrínseca, faz parte do modelo capitalista.

Nesse contexto, o regime de acumulação flexível também possui um sistema de produção e de organização do trabalho que serviu como materialidade desse processo: o toyotismo. De acordo com Peinado e Graeml (2007), a ideia do sistema Toyota de produção - como ficou conhecido - surgiu no Japão, após a Segunda Guerra Mundial, dentro da própria fábrica da Toyota Motors Company. Esse programa de qualidade na produção tinha algumas particularidades e objetivos, a saber,

O sistema surgiu como resposta ao
elevado nível de complexidade e
precisão exigido pelo sistema
tradicional ... O objetivo era tornar
simples e rápidas as atividades de
programação, controle e
acompanhamento da produção em
lotes, em relação à complexidade
trazida pelo uso de computadores na
indústria. (Peinado \& Graeml, 2007,
p. 449).

Acima, cita-se uma particularidade técnica que evidencia os motivos que propiciaram a sua idealização, ou seja, contrapor-se ao sistema tradicional (Fordismo), disseminado pela Europa e Estados Unidos. Do ponto de vista produtivo, a principal estratégia desse modelo era fabricar o máximo possível de produtos visando reduzir os custos de produção. Isso gerou altos níveis de estoque que dependiam de iniciativas de fomento, tanto das empresas, quanto do Estado para criar potenciais consumidores. Por outro lado, as crises econômicas começaram a ocorrer com mais frequência, a exemplo da crise do petróleo de 1973, momento em que os mercados entraram em queda e países em recessão econômica. Ademais, o Japão estava devastado desde a Segunda Guerra, sua economia passava por reestruturações por parte dos países vencedores, como os Estados Unidos. Estes e outros fatores complexos foram 
motivadores para o surgimento do toyotismo no Japão (Ohno, 1997).

O surgimento da microeletrônica impulsionou novos padrões de trabalho e produtividade, de acordo com Kuenzer (2007, 2018) esse sistema de produção pediu um novo tipo de trabalhador, o multitarefa, aquele que não se atinha somente a um tipo de atividade, mas analisava e atuava em vários processos. Com isso houve mudanças nos padrões de formação profissional, que pediam: um sujeito preparado para execução de atividades envolvendo trabalho em equipe, realização de diagnósticos, correção dos problemas identificados, que realizaria capacitações constantes, isto é, um profissional que exercesse todas as competências necessárias para o bom andamento da indústria.

Partindo desse enfoque, esse sistema possuía algumas características transitórias herdadas do fordismo: treinamento com diferenciação para operadores e chefias, controle do tempo, aprimoramento dos movimentos e eficiência na execução das atividades. Intensificou-se no seu processo de readequação a redução dos postos de trabalho e houve um enxugamento do corpo funcional das empresas, os gerentes ou proprietários buscavam a todo custo reduzir o efetivo, sobrecarregando com multitarefas boa parte dos trabalhadores.
O fato é que o mercado internacional recebeu muito bem a perspectiva que nasceu no território oriental. As práticas administrativas, econômicas e de produção toyotistas foram ajustadas nos países desenvolvidos como solução para a crise que se encontrava com base no fordismo. Harvey (1992, p. 140-141) definiu o que seria o regime de acumulação flexível e afirma a emergência desse novo modelo econômico, social e político de impactos significativos para o mundo.

\begin{abstract}
A acumulação flexível como vou chamá-la, é marcada por um confronto direto com a rigidez do fordismo. Ela se apoia na flexibilidade dos processos de trabalho, dos mercados de trabalho, dos produtos e padrões de consumo. Caracteriza-se pelo surgimento de setores de produção inteiramente novos, novas maneiras de fornecimento de serviços financeiros, novos mercados e, sobretudo, taxas altamente intensificadas de inovação comercial, tecnológica e organizacional. A acumulação flexível envolve rápidas mudanças dos padrões do desenvolvimento desigual, tanto entre setores como entre regiões geográficas, criando, por exemplo, um vasto movimento no emprego no chamado "setor de serviços", bem como conjuntos industriais completamente novos em regiões até então subdesenvolvidas. (Harvey, 1992, p. 140-141).
\end{abstract}

De acordo com a ideia supracitada, o pesquisador identifica que o excesso de mão de obra disponível no mercado causou importante fragmentação no sindicalismo, reforçada principalmente pela crise 
econômica. Essa realidade abriu um leque de possibilidades para o toyotismo se alicerçar nas economias capitalistas.

Saviani (2007, p. 159) assevera que no toyotismo as atividades de manutenção, reparos, ajustes técnicos eram necessárias para o funcionamento das máquinas na linha de produção, atividades que surgiram do próprio processo de automação industrial. Para isso, os trabalhadores necessitavam de formação que até então a escola básica não dispunha. Para atender a esse preparo intelectual e manual específico se instituíam os cursos profissionais, que poderiam ser organizados tanto pelas empresas que necessitavam de formações específicas ou pelos "sistemas de ensino, tendo como referência o padrão escolar, mas determinados diretamente pelo processo produtivo".

No meio desse embate, o trabalhador se encontrava em um processo de profunda transição: de um sistema de locação de mão de obra maciça com foco em atividades mecânicas, individualistas, com longas horas de trabalho, para um sistema volátil, pautado em atividades multitarefas, de prestação de serviços temporários, com carga horária reduzida, além da necessidade de formação educacional tanto técnica, quanto teórica, estas oferecidas de forma seletiva.
Tanto o regime rígido quanto o flexível influenciaram na criação de matrizes ideológicas de caráter educacional, que se pautavam em desenvolver formas de disciplinamento do trabalhador. As estratégias utilizadas foram criar novas terminologias e noções para gerar no imaginário das pessoas a noção de modernidade, artifício que acompanhou o aprimoramento tecnológico e das relações de trabalho. A concepção de competência, termo bastante utilizado nas últimas décadas, representa essa estratégia. Requer um novo tipo de trabalhador, aquele que terá que adequar-se a padrões de formação pré-determinados pelo mercado, tendo que desenvolver conhecimentos, habilidades e atitudes específicas, sem os quais não conseguirá adentrar no mercado de trabalho competitivo.

\section{O trabalhador competente: a nova exigência da acumulação flexível}

As novas demandas comerciais, educacionais e de trabalho criadas a partir do aprimoramento das tecnologias foram incorporadas pelo capitalismo e, como estratégia, foi necessário criar um imaginário que representasse essa modernidade e de certa forma apagasse as iniciativas que não deram certo, nada melhor que inventar novos termos para 
repaginar ações que no seu interior possuem a mesma dinâmica.

Bourdieu e Wacquant, citados por Frigotto e Ciavatta (2006), demonstram as transformações que ocorreram nos vocábulos, conceitos ou noções a partir dos últimos anos do século $\mathrm{XX}$, descrevendo como nova língua as constantes mudanças, repaginações e substituições de conceitos por outros. Frigotto e Ciavatta (2006) afirmam que essas novas vulgatas surgiram com a (des)ordem mundial e da ideologia neoliberal ${ }^{\text {iii }}$.

Ademais, os autores afirmam que os altos funcionários de empresas, jornalistas, intelectuais apresentaram nos últimos anos um vocabulário novo: "globalização, flexibilidade, multiculturalismo, empregabilidade" e competências entre outros, termos que até então não existiam, criando assim o "novo", algo que poderia representar as novas tendências mundiais. Vocábulos como "capitalismo, classe, exploração, dominação, desigualdade tornam-se obsoletas neste novo contexto mundial". (Bourdieu \& Wacquant, apud Frigotto \& Ciavatta, 2006, p. 56).

Essa imposição simbólica está entranhada nas mais diversas camadas das classes sociais, isto é, não é representada somente pelos adeptos liberais, mas por intelectuais, políticos e educadores, estando enraizada até nos movimentos que lutam contra o capitalismo.

Noam Chomsky ... consagrado lingüista e hoje um dos mais importantes intelectuais críticos do capitalismo das megacorporações, ao analisar o sentido histórico e humano do II Fórum Social Mundial - 2002 mostra como o termo globalização, que na tradição da I e II Internacional Socialista tem o sentido de internacionalismo, de solidariedade entre os seres humanos e de partilha dos bens do mundo, é apropriado pelos detentores do grande capital na perspectiva dos processos predatórios, em nome do lucro. (Frigotto \& Ciavatta, 2006, p. 57).

O modo como o capitalismo se apropriou de determinados termos para criar efeitos de sentido do novo repercutiu também nas práticas pedagógicas, as quais pretendem formar o tipo de sujeito que caberia nessa realidade. Deste modo, tratase da noção de "competência". Essa noção que atravessa a prática pedagógica influencia novamente a formação do trabalhador, pois parte de um pressuposto que define os critérios básicos para o seu desenvolvimento e potencialidades das pessoas, atendendo os moldes do trabalho moderno.

Como assevera Araújo (2004, p. 498499), a emergência da noção de competência é por si só complexa e levanta vários entendimentos. Ao investigar os possíveis pontos de partida que influenciaram a emergência desse conceito, 
o autor levanta alguns acontecimentos: a crise dos regimes de acumulação rígida e flexível, "a resistência operária ao trabalho fragmentado e repetitivo; a globalização da economia; o progresso das tecnologias de produção e de processamento das informações, o aumento das políticas neoliberais" e gostaríamos de incluir nessa relação o foco na informação.

Chiavenato (2010) afirma que esses acontecimentos geraram significativas mudanças nos requisitos da força de trabalho e consequentes alterações nas formações educacionais. As organizações tendem a ajustar de forma constante sua atuação no mercado, seja para adequar-se às mudanças sociais, políticas e tecnológicas ou para criar novas tendências, tais oscilações afetam diretamente a classe trabalhadora.

Em uma perspectiva empresarial, o conceito de competência é utilizado como um dos principais parâmetros para direcionar os processos formativos e de gestão de pessoas. Contudo, o compartilhamento do conhecimento ainda é seletivo, somente poucos possuem acesso. Por outro lado, têm-se as informações técnicas de nível prático e de pouco aprofundamento teórico necessárias ao desenvolvimento das competências que são disseminadas principalmente para o trabalhador.
Diversos pesquisadores trabalham sobre o tema, entre eles Gil (2001), Fleury e Fleury (2004) e Chiavenato (2010), evidenciando em seus trabalhos que a competência está ligada ao conjunto de conhecimentos, habilidades e atitudes (CHA) que determinado profissional deve desenvolver para execução de suas atividades no trabalho.

Para Fleury e Fleury (2004, p.185), o conceito de competência,

... é pensado como conjunto de conhecimentos, habilidades e atitudes (isto é, conjunto de capacidades humanas) que justificam um alto desempenho, acreditando-se que os melhores desempenhos estão fundamentados na inteligência e personalidade das pessoas. Em outras palavras, a competência é percebida como estoque de recursos, que o indivíduo detém. Embora o foco de análise seja o indivíduo, a maioria dos autores americanos sinalizam a importância de se alinharem as competências às necessidades estabelecidas pelos cargos, ou posições existentes nas organizações.

Os autores afirmam que o foco é o “ajuste do indivíduo", que está vinculado diretamente aos padrões estabelecidos pelas empresas nas três dimensões do CHA, vejamos: os conhecimentos são desenvolvidos com base nos processos formativos que são disponibilizados por meio das diversas formas de educação; as habilidades estão na esfera das práticas e são aprimoradas com o tempo de trabalho 
e, por fim, as atitudes podem ser definidas

a partir das iniciativas proativas do trabalhador frente aos problemas que surgem (Gil, 2001; Chiavenato, 2010).

Deste modo, o trabalhador exerce sobre si mesmo uma pressão contínua para adequar-se a esses padrões de referência profissional, tomando a responsabilidade de aprimorar-se de forma constante. O discurso reiterado é que o mercado só absorve os considerados melhores, ou seja, aqueles que se adéquam aos padrões propostos. Para isso o mercado elegeu áreas de saber que são importantes para o sucesso ou fracasso empresarial.

Essa forma de se pensar um trabalhador competente carrega ideologias que orientam suas ações, realidade discutida por Araújo (2004), momento que a pedagogia das competências, termo mais amplo para designar esse emaranhado de práticas profissionais e educacionais, sofre influência direta do racionalismo e do individualismo. Essas marcas ideológicas possuem raízes profundas presentes desde os estudos de Frederick Taylor (18561915) durante a primeira revolução industrial, que se redefinem e se realinham conforme as mudanças que ocorrem a nível social, econômico, político e cultural. Como exemplo o surgimento na década de 1970 "da corrente tecnicista baseado na Teoria do Capital Humano... na década
1990 como neotecnicismo, inspirado nos Círculos de Controle de Qualidade". (Araújo, 2004, p. 502).

O racionalismo está subjacente também nas ações de formalização das competências, nas práticas que visam os objetivos formativos comprometidos com a máxima eficiência dos sistemas educacionais tendo em vista $\mathrm{o}$ atendimento das demandas dos setores produtivos. $\mathrm{Na}$ medida em que torna públicos os objetivos e os critérios de competência, essa orientação racionalista abre espaço para $o$ controle das ações de autoformação e auto-avaliação dos indivíduos. A idéia de racionalização também vem inspirando práticas de avaliação que se propõem medir objetiva e rigorosamente as competências de alunos e trabalhadores. Em tais práticas, onde se empregam métodos e técnicas supostamente científicas, são utilizados procedimentos de objetivação, de classificação e de medida das competências requeridas, das competências adquiridas e do percurso profissional. (Araújo, 2004 p. 503).

Como podemos evidenciar, essa expressão carrega em seu interior características que atestam a imbricação dos modelos rígido e flexível. Tais modelos receberam uma repaginação de moderno a fim de tentar esconder suas contradições, mas seus objetivos estão claros: disciplinar o trabalhador ao máximo e moldá-lo conforme as demandas econômicas que surgirem.

Percebe-se que diferentes formas de ensino foram criadas para adequar-se aos 
objetivos daqueles que estão no poder, permanecendo a dualidade educacional já evidenciada. Importante ressaltar que no desenvolvimento do processo industrial o mercado não deixou de investir na formação do trabalhador, aliás, com o aprimoramento da tecnologia houve necessidade de aumentar as exigências e formações para o trabalho, inserindo $\mathrm{o}$ trabalhador numa dinâmica frenética de autoformação, para assim, aliar-se aos padrões de competência exigidos pelo mercado de trabalho. Na próxima seção debateremos sobre o PRONATEC, materialidade dessa dinâmica de formação direcionada ao camponês.

\section{PRONATEC: Um "novo" projeto de formação do trabalhador}

As políticas públicas instituídas no Brasil a partir da década de 1990, principalmente as que estão relacionadas à formação do trabalhador, foram influenciadas pelas novas relações de trabalho que emergem junto às exigências do mercado internacional e da ideologia neoliberal. Essas políticas em sua maioria feita às pressas sem levar em consideração as reais demandas sociais e econômicas do país, são justificadas pela constante necessidade de "qualificar" a mão de obra ociosa e não produtiva. Essa estratégia há tempos utilizada pelo mercado e pelos governos para manter essa dinâmica em funcionamento.

Na primeira década do século XXI, de forma específica entre os anos 2003 a 2010, período de governo do então Presidente Luiz Inácio Lula da Silva, várias mudanças no cenário político, econômico e social emergiram. Foi um momento de políticas que ampliaram a distribuição de renda, de ajustes nas metas de inflação, de valorização do salário mínimo, por consequência, novos grupos sociais aumentaram sua parcela no consumo de bens e serviços, isto é, houve um pico de crescimento da economia (Ribeiro, 2014).

Segundo Ribeiro (2014), durante esse período a formalização de empregos diretos com carteira assinada atingiu índices significativos, várias pessoas passaram a integrar essa esfera, seja no âmbito da cidade ou do campo. $\mathrm{O}$ aumento da arrecadação tributária beneficiava as políticas de valorização salarial; as iniciativas empreendedoras cresciam deixando o mercado frenético, alguns economistas citavam que o regime de acumulação flexível, de fato, havia emplacado no país.

Todavia, esse momento histórico que parecia consagrar as influências do capitalismo, é interrompido por uma crise mundial ao final da década de 2000. No 
meio dessa transição o governo da então Presidenta Dilma Rousseff recebeu os problemas gerados pela política econômica e social implantada, além da crise econômica que assolava o mundo capitalista: desemprego em massa, política de proteção e incentivos fiscais, estimulo às empresas, formalização forçada dos setores informais foram as medidas emergenciais enfrentadas pelo novo governo (Nascimento, 2016).

Diante desse panorama surge o PRONATEC, como mais uma iniciativa no meio de tantas idealizadas e descontinuadas a cada novo governo. Neste caso, bastante influenciada pelas duas últimas políticas de formação profissional instituídas no país: o Plano Nacional de Educação do Trabalhador (PLANFOR) do governo Fernando Henrique e o Plano Nacional de Qualificação (PNQ), do governo Lula. Para articular a implementação do PRONATEC, o governo fundiu numa única Lei, várias outras que destinavam a utilização de recursos públicos e da iniciativa privada, exemplo do Fundo de Amparo ao Trabalhador (FAT), Seguridade Social, Fundo de Financiamento do Ensino Superior, Programa Nacional de Inclusão de Jovens (PROJOVEM), com intuito de padronizar e articular melhor as ações nas diversas esferas públicas e privadas que ofertariam os cursos (Silva, 2014).

Iniciativa instituída pelo governo federal no ano de 2011, por meio da Lei 11.513, de acordo com o documento, seu principal objetivo é "expandir, interiorizar e democratizar a oferta de cursos de educação profissional e tecnológica no país, além de contribuir para melhoria da qualidade do ensino médio público" (Brasil, 2011). A proposta era disponibilizar formação técnica em médio e curto prazo, visando atender as demandas do mercado. Outro ponto está na parceria com várias instituições: Rede Federal, Estadual, Municipal, em especial do Sistema "S", entidades privadas experientes no treinamento profissional, assistencial social, consultoria, pesquisa e assistência técnica, formadas pelo: SENAI, SESC, SESI, SENAC, SENAR, SEST e SESCOOP.

O programa possui como público alvo e prioritário os seguintes beneficiários: estudantes do ensino médio da rede pública, inclusive da Educação de Jovens e Adultos; trabalhadores, que incluem agricultores familiares, silvicultores, aquicultores, extrativistas e pescadores, entre outros; beneficiários dos programas federais de transferência de renda, estudantes bolsistas. Participaram indígenas, quilombolas, adolescentes e 
jovens em cumprimento de medidas socioeducativas e mulheres beneficiárias de programas de transferência de renda, nos cursos de bolsa-formação (Brasil, 2011).

Várias são as ações que fazem parte do leque de atuação do programa, estas dão continuidade às diversas iniciativas de ampliação de vagas para formação profissional. Como exemplo do projeto de expansão da rede Federal de ensino e rede estadual: oferta de bolsas de estudo para estudantes e trabalhadores, em especial os beneficiários de programas sociais, entre outros.

Neste sentido, Castioni (2013) afirma que a atuação principal do MEC se pautava na organização do sistema escolar, mas ao assumir a responsabilidade de organizar o PRONATEC, cujo foco principal é a formação para o trabalho, lhe faltou organicidade e experiência. Segundo o pesquisador, as parcerias feitas com o sistema "S" tomaram duas perspectivas distintas: a primeira benéfica do ponto de vista técnico, pois o programa se alia a entidades que possuem experiência significativa e histórica sobre o tema (formação do trabalhador), além de possuir boa estrutura e número expressivo de professores.

Em contrapartida, essa parceria fragmentou as iniciativas com a rede pública, castigada há décadas com baixo investimento. Essas iniciativas, para se firmarem, necessitam de muito mais investimentos em estrutura e professores para garantir a absorção de toda a demanda idealizada pelo programa, isto é, acreditase que em pouco tempo os recursos tenderão a ser reduzidos e direcionados para a rede privada.

A partir do seu entendimento sobre as parcerias público-privadas envolvendo a formação profissional, Lima (2012) afirma que tendem a surtir efeitos danosos ao processo educacional no Brasil, tendo em vista que o Estado se coaduna ideologicamente com o neoliberalismo. Essa atitude deixa margem para atuação da iniciativa privada, permitindo que compartilhem a responsabilidade de formar o trabalhador da sua maneira e quase sem intervenção do Estado, intensificando por consequência a mercantilização da educação.

Acreditamos que essa mercantilização pode ser vislumbrada na formação humana com base em dois indicadores: 1) a fragmentação e a desarticulação curricular, que indicam a aceleração dos tempos formativos, fruto do pragmatismo, do utilitarismo pedagógico que tende a implantar configurações curriculares que desprezam os vínculos epistêmicos existentes entre teoria e prática, entre formação geral e formação específica; 2) as novas formas de esvaziamento da intervenção do Estado, que pseudo criam direitos validados pela via 
meritocrática sustentada pelo financiamento público de bolsas de estudos que reiteram as parcerias público-privadas. (Lima, 2012, p. 77).

Além disso, segundo a Cartilha do Pronatec Campo (2011), os cursos oferecidos pelo programa se escalonam nas seguintes modalidades, primeiro de formação inicial e continuada, conhecidos com cursos de Formação Inicial Continuada (FIC), que são considerados de curta duração com carga horária mínima de 160 horas, direcionado para aqueles beneficiários do seguro-desemprego e de programas inclusivos do governo federal. Os alunos interessados podem estar cursando ou nem ter concluído o ensino fundamental, situação que caracteriza a formação direcionada de forma exclusiva para atender as demandas do mercado, realidade que não garante o emprego, mas reforça a necessidade de fomentar a indústria da certificação.

Os cursos de média duração oferecidos aos alunos que frequentam os médios técnicos (integrados) nas Instituições Públicas Federais e Estaduais a carta horária chega a mais 800 horas-aulas. O ponto forte do programa está nos cursos de curta duração, que reforça o caráter compensatório e de dualidade educacional há tempos inserido no panorama educacional brasileiro.
Para nós, não resta dúvida de que se trata de um programa inserido no contexto da acumulação flexível capitalista brasileira,no momento em que as taxas de desemprego são as mais baixas da história brasileira. É um programa inserido em um quadro no qual o governo trata de trazer para o mercado de empregos trabalhadores até então excluídos por variadas razões econômicas, sociais, políticas e culturais. Um programa de inclusão dos excluídos, com objetivo de garantir a oferta de mão de obra com baixos salários, no intuito de reduzir a pressão por elevações salariais e de tornar viável a expansão das relações capitalistas no país. (Ribeiro, 2014, p. 17).

O embate envolvendo a profissionalização no Brasil é pauta de reivindicações, tanto dos movimentos sociais e intelectuais que lutam por uma educação igualitária e ampla, quanto pelo mercado que busca utilizá-la para a formação de sua mão de obra. Na maioria das vezes, os interesses dos grupos econômicos são atendidos, pois pressionam governos a atuarem em seu favor na elaboração de leis que propiciam a massificação da força de trabalho. Essa ação não é novidade olhando numa perspectiva histórica e o PRONATEC é um exemplo disso (Silva, 2014).

Ao final desta seção, pode-se evidenciar que o PRONATEC, além de refletir contradições inerentes ao processo capitalista de formação para o trabalho, apresenta em sua formulação caráter assistencialista e de efeito temporário, fato 
que se repete a cada "crise" de mão de obra quando a formação para o trabalho passa a ser direcionada somente aos sujeitos considerados excluídos do processo produtivo.

\section{Instituto Federal do Tocantins, campus Araguatins e o PRONATEC Campo}

Entre os anos de 2013 a 2014, o Instituto Federal do Tocantins passou a ofertar cursos de curta duração vinculados ao PRONATEC. Enfatiza-se que o PRONATEC Campo é uma das modalidades pertencentes ao conjunto de estratégias de atuação do PRONATEC, criada para atuar na formação profissionalizante do camponês. Nesta modalidade os cursos de FIC são o foco principal. Essa modalidade surgiu em atendimento ao descrito no parágrafo I, do artigo $2^{\circ}$ da lei que instituiu o PRONATEC, ou seja, disponibilizar formação também para os trabalhadores do campo, cujo objetivo principal é:

Promover espaços de qualificação profissional de agricultores e agricultoras, integrando às demais políticas de desenvolvimento rural sustentável e solidário. Objetivos específicos: qualificar o acesso às políticas de inclusão social e produtiva do meio rural; Oportunizar a inclusão sócio produtiva e econômica dos/as agricultores/as familiares, priorizando as juventudes do compõe focando na integração da formação com as estratégias de desenvolvimento rural sustentável e solidário; Estimular o intercâmbio de conhecimentos, adotando os princípios da agroecologia como modelo de desenvolvimento rural sustentável; Apoiar o desenvolvimento de metodologias para promover processos de diversificação da produção e a transição agroecológica; Priorizar a produção para garantir a segurança alimentar e nutricional da família e comunidade...; Criar oportunidades para o/a jovem permanecer no campo e fortalecer os processos de sucessão na agricultura familiar; Qualificar a gestão das unidades de produção familiar, cooperativas e agroindústrias e Promover a organização social, produtiva e o acesso a mercados institucionais e privados. (Brasil, 2011, grifo nosso).

Os objetivos direcionados ao PRONATEC Campo parecem amplos e focam em formações de média e longa duração, integradas ao ensino médio, que num primeiro momento são ofertados por instituições da rede Federal. Entretanto, existe um problema que escapa na malha ideológica do programa e demonstra seu real propósito: influenciar os camponeses nos moldes capitalistas de mão de obra para o mercado de trabalho na ideologia da acumulação flexível.

Estes cursos, geralmente são nas áreas técnica em agropecuária, silvicultura, auxiliar técnico em agropecuária, apicultura, cooperativismo entre outros. Todos os cursos são interessantes, no entanto, o formato de curto prazo é oposto à política de Educação do Campo pensada pelos movimentos sociais, que veem a 
formação profissional pertencente a um contexto amplo, conectada a outros aspectos educacionais e informais, ao contrário dos cursos de curta duração com viés mercantilista, com intuito a fomentar somente o aumento de certificação.

Sendo assim, percebe-se que essa mesma dinâmica de reprodução está sendo transferida para dentro dos assentamentos rurais: de criar uma força de trabalho homogênea, que entende a atividade do campo como negócio, competitivo e especializado. Realidade que tende a desconstruir a cultura do homem do campo, o rotulando como desqualificado, que não possui conhecimento técnico, que este não consegue manter-se em sua terra por incompetência e necessita ser qualificado (Fernandes \& Molina, 2004).

Ao analisar esse contexto sob o ponto de vista econômico produtivo, infere-se que o Estado propõe por meio dessas ações que o camponês profissionalize-se para adentrar o mercado de trabalho, a cada dia mais competitivo. Porém, essa fórmula não funciona quando se observa o histórico de lutas e embates do camponês contra esse tipo de iniciativa.

No caso das populações do campo, no âmbito dos cursos oferecidos, por mais que seja direcionada as suas demandas, a forma que é aplicada é semelhante à da zona urbana, ou seja, de forma padronizada e com foco para o mercado de trabalho, não conciliando com as práticas do campo em que estes sujeitos estão inseridos (Fernandes \& Molina, 2004).

No Tocantins, o PRONATEC iniciou sua atuação pela Secretaria do Trabalho e da Assistência Social, designado como: Tocantins Sem Miséria em 2013, acompanhando o mesmo formato do projeto governamental Brasil Sem Miséria. Nas reuniões iniciais junto aos gestores municipais, foram apresentados o projeto e as formas de adesão aos cursos e informado sobre seu funcionamento (Tocantins, 2013).

O documento base do programa orientava as estratégias de Adesão e de habilitação dos municípios interessados nos cursos. Inicialmente, a organização do processo em sua maioria era de responsabilidade da Secretaria Municipal de Assistência Social de cada município, que se responsabilizava por realizar o levantamento da necessidade de formação, os cursos em geral eram direcionados ao público urbano. Com as novas formas de organização do programa, outras instituições públicas fizeram parte, como veremos.

O IFTO/Campus Araguatins foi a primeira instituição federal a oferecer cursos do PRONATEC Campo no estado do Tocantins, atendendo as demandas do 
Ministério do Desenvolvimento Agrário (MDA) em conjunto com o Instituto Nacional de Colonização e Reforma Agrária (INCRA). No início do primeiro semestre de 2013, o campus Araguatins já havia certificado 300 alunos. Destes, 120 alunos no curso de Auxiliar Técnico em Agropecuária vinculado ao PRONATEC Campo (IFTO, 2013).

Os cursos ofertados pela Instituição foram selecionados por uma combinação de esforços e de informações, de acordo com as demandas identificadas pelos demandantes nacionais e pelas necessidades apresentadas pela população local por meio de pesquisas nas cidades e de reuniões com prefeituras das respectivas cidades e por demanda apresentada pelo Governo Estadual, por meio da Secretaria de Educação e de Assistência Social e pelo Ministério do Desenvolvimento Agrário através de sua Delegacia Regional no Tocantins. (IFTO, 2013, p. 4).

No ano de 2014, o IFTO Araguatins havia pactuado junto com as instituições demandantes - incluindo solicitações de vários cursos do PRONATEC, inclusive os do PRONATEC Campo -, a "oferta de 676 vagas em 17 ofertas de cursos FIC que variavam entre 160 e 240 horas. Os cursos foram: pedreiro, auxiliar de crédito e cobrança, piscicultor e vendedor" (IFTO, 2013, p. 6-7).

Os cursos de horticultor orgânico, apicultor, auxiliar em agropecuária e agente de desenvolvimento cooperativista foram ministrados diretamente nos assentamentos. Neste mesmo ano também foi disponibilizado o curso Técnico de Informática para Internet concomitante com o ensino médio, que teve carga horária de 1.000 horas (IFTO, 2013).

Em alguns casos, a dificuldade para o deslocamento dos professores era significativa, pois para chegar a determinados assentamentos os professores percorriam de moto ou caminhonete, a exemplo deste pesquisador que para chegar no assentamento "Mártires da Terra" formado por camponeses do Movimento Sem Terra (MST), localizado no município de São Bento, que fica a $60 \mathrm{~km}$ de Araguatins, percorreu de moto $33 \mathrm{~km}$ de estrada de chão, totalizando $93 \mathrm{~km}$ até o assentamento. Além das adaptações para ministrar a aula no barracão. Os cursos foram ministrados em outras cidades, além de Araguatins, totalizando 06 municípios (IFTO, 2013).

A partir destes dados, podemos inferir que o foco nos cursos de curta duração foi o marco desse programa, possivelmente pela maior disponibilidade financeira por parte do governo federal, além da facilidade logística da sua execução, exceto os cursos que ocorriam em assentamentos. $\mathrm{O}$ orçamento pactuado para realização de todos os cursos pela 
instituição no ano de 2014 "chegou a R\$ 1.100.341,45; destes, os valores efetivamente pagos foram de $\mathrm{R} \$$ 979.500,30” (IFTO, 2013, p. 19).

Após dois anos de experiência em cursos do PRONATEC, o IFTO passou a compartilhar experiências para os demais Campi do estado, principalmente na estratégia logística e de ensino que foi aprimorada no tratamento dos cursos FIC nos assentamentos. A demanda para cursos em assentamentos para o ano de 2015 era ainda maior, com previsão para mais de 10 assentamentos e acampamentos.

No entanto, devido às constantes mudanças que ocorreram no âmbito das políticas públicas nesse segmento, o governo federal reduziu consideravelmente a pactuação e financiamento dos cursos do PRONATEC Campo, findando totalmente as atividades no campus em 2016. Os recursos foram destinados gradativamente para o sistema "S", que na região está representado pelo Serviço Nacional de Aprendizagem da Agricultura (SENAR), que até o presente momento da produção deste trabalho realiza cursos destinados aos assentados com pactuações com o governo federal, mantendo-se a dinâmica de prevalência de investimentos em instituições privadas com foco no mercado e no disciplinamento do trabalhador do campo.

\section{Metodologia}

A proposta em análise é de interpretar os efeitos de sentido (memórias discursivas) que emergem no discurso do Projeto Pedagógico do Curso de Auxiliar Técnico em Agropecuária, ofertado pelo Instituto Federal do Tocantins, campus Araguatins, vinculado ao PRONATEC Campo, destinado aos camponeses de vários assentamentos pertencentes à cidade de Araguatins, estado do Tocantins.

Para tanto, elegeu-se como norteador desse processo a Análise de Discurso Francesa (AD), com base nos estudos de Pêcheux (1999), Achard (1999) e Orlandi (1999), os quais discutem sobre memória discursiva, interdiscurso e efeitos de sentido. Pois se entende que tal projeto reflete memórias que articulam designações relacionadas à concepção do sujeito trabalhador num ambiente capitalista.

O termo memória discursiva remete a um discurso que está implícito, que é retomado pelo sujeito de forma não intencional, geralmente são materializados pela paráfrase: uma forma de apresentar um já dito anterior que emerge da memória histórica do enunciador. Para Achard (1999, p. 14), "De outro modo, o passado, mesmo que realmente memorizado, só pode trabalhar mediante as reformulações 
que permitem reenquadrá-lo no discurso concreto face ao qual nos encontramos".

O interdiscurso é um conjunto de efeitos de sentido que estão ligados a uma memória ou várias memórias discursivas (Orlindi, 1999). Todos os efeitos de sentidos que são postos na arena do dito emergem, necessariamente não foram ditos explicitamente e podem ter relação direta com o não dito, podemos dizer que apareceram por conta da existência de questões sociais e históricas que afetam o discurso.

\section{Resultados e discussões}

$\mathrm{Na}$ seção anterior, buscou-se explicitar o principal dispositivo teórico que foi utilizado para o desenvolvimento desta análise: a noção de memória discursiva. Pêcheux (1999, p. 51) reforça que "a memória deve ser entendida não no sentido de memória individual, mas nos sentidos entrecruzados da memória mítica, da memória social escrita em práticas, e da memória construída pelo historiador". Portanto, a pesquisa tem como objetivo demonstrar no corpus do PPC, que serviu de objeto desse estudo, o momento em que esse dispositivo é acionado.

\section{O sujeito competente no exercício da cidadania}

Enunciado 1: “...preparar indivíduos para o exercício da cidadania, promover a consciência social, formar técnicos competentes e atuantes na sociedade". (IFTO, 2013, p. 4, grifo nosso).

Neste primeiro momento, as seguintes marcas discursivas retiradas do corpus de análise são: técnicos competentes e exercício da cidadania. Os motivos históricos, sociais e econômicos que influenciaram na produção desse discurso carregam em si posições ideológicas conflitantes e que de certo modo aparecem no discurso do PPC como se estivessem condicionadas umas as outras.

Para analisar o enunciado competente em seu sentido polissêmico, é interessante apresentá-lo de outro modo, para isso se buscou uma definição do ponto de vista formal. Com a ajuda do dicionário organizado por Scottini (1998, p. 122), entende-se que competente é o: "capaz, idôneo, bastante, suficiente, preciso e indispensável". Em perspectiva complementar, na pesquisa relacionada à reforma da educação profissional no Brasil, do ponto de vista das competências, Araújo (2002, p. 4) a define como a "capacidade pessoal de articular autonomamente os saberes (saber, saberfazer, saber-ser e saber-conviver) inerentes a situações concretas de trabalho".

Dentro dessa perspectiva, essa "nova" roupagem toma a noção de 
competência e a interliga a memórias históricas que buscam aliá-la ao "desenvolvimento das capacidades humanas, ao progresso econômico, a redução da desigualdade, a felicidade dos trabalhadores", condicionantes que ajudam na inserção do indivíduo nos processos democráticos e ao exercício da cidadania capitalista (Araújo, 2002 p. 6). Esses sentidos podem ser observados claramente nos enunciados descritos nas seções que tratam da justificativa e do perfil do egresso do curso, a saber: "melhor qualidade de vida; trabalho decente, mão de obra qualificada, administrar propriedades rurais, monitorar sistemas de produção, planejar, executar, acompanhar...”. (IFTO, 2013, p. 8).

Outra marca que ficou evidente no discurso é a inclusão do enunciado, exercício da cidadania, prática social que inclui determinado sujeito dentro da complexa rede de relações numa sociedade democrática. Exercer a cidadania é ter direitos e deveres numa determinada sociedade. Segundo Scottini (1998, p. 114), cidadão é "quem mora numa cidade, quem possui todos os direitos civis e políticos".

Tomando por base o contexto que influencia a produção discursiva do PPC, esse enunciado remete a sentidos que deduz para se exercer a cidadania o sujeito deve estar inserido no mundo do trabalho, isto é, ser produtivo. Evidencia-se de forma complementar esses sentidos/memórias nos enunciados: "favorecendo o desenvolvimento da economia, suprir a necessidade dos empreendimentos por mão de obra". (IFTO, 2013, p. 8).

Para debater essa questão, foram utilizados ou utilizou-se o estudo de Frigotto e Ciavatta (2006), que desenvolveram uma pesquisa com objetivo de analisar as contradições pertinentes aos projetos de formação profissional existentes no Brasil. Nesta pesquisa, explicitam as diferentes concepções ideológicas que permeiam as noções de "cidadão" e "cidadania" no mundo capitalista.

Uma memória histórica que atravessa o enunciado é a integração da concepção de cidadania ao trabalho produtivo. Essa concepção fez com que significativa parcela dessas populações, antes excluídas das relações políticas, fosse inserida nesse processo, não pelo seu direito constitucional ou pelos embates sociais que surgiram como forma de resistência, mas pelo seu papel de gerador de riqueza numa economia de mercado, que evidencia a produtividade, a geração de competências e a empregabilidade. 
Nesta relação os efeitos dos investimentos educacionais tornaram-se indispensáveis para a manutenção desse sistema, ou seja, o sujeito passa a ser responsável pelo seu sucesso ou fracasso, sendo excluída a responsabilidade do Estado e das constantes mudanças no mercado de trabalho orientadas pelas tendências do capitalismo.

Passa-se a ideia de que a
desigualdade entre nações e
indivíduos não se deve aos processos
históricos de dominação e de relações
de poder assimétricas e de relações
de classe, mas ao diferencial de
escolaridade e saúde da classe
trabalhadora. Associam-se, de forma
linear, a educação, o treinamento e a
saúde à produtividade... de
desenvolvimento e de busca do pleno
emprego. (Frigotto \& Ciavatta, 2006,
p. 51).

Nesta concepção, a inserção na sociedade está fadada à própria integração do sujeito aos moldes estabelecidos pelas convenções do mercado. A inserção do trabalhador flexível nesta sociedade está ligada ao seu nível de empregabilidade e competências conquistadas pelas constantes atualizações profissionais adquiridas ao longo dos anos, ou seja, nessa linha ideológica, somente quem exerce a cidadania é o sujeito que se emoldura dentro desses padrões.

A marca consciência social que aparece no enunciado analisado age de forma complementar ao exercício $d a$ cidadania, isto é, a prática de exercer a cidadania num ambiente favorável à promoção de iniciativas que incluam o sujeito ativo no ambiente socioeconômico e político é de suma importância, pois agrupar projetos sociais que geram tanto a riqueza econômica, quanto a valorização do humano são características que representam a consciência social. No entanto, essas concepções se confrontam quando é retomada a memória da noção de competência técnica como condição para o exercício da cidadania.

\section{Educação e trabalho: juntos, no entanto, separados}

Enunciado 2- “... O PRONATEC representa, entretanto, mais do que, o cumprimento de uma obrigação formal... É também e acima de tudo o instrumento de consolidação de uma política pública visando a aproximar mundo do trabalho do universo da Educação". (IFTO, 2013, p. 7).

As marcas discursivas, trabalho e educação, sem dúvida são os principais conceitos trabalhados nesta pesquisa, suas noções sofreram modificações ao passar dos tempos e tomaram novos rumos com o desenvolvimento das práticas humanas.

$\mathrm{O}$ fato interessante é que o enunciado remete a uma possível separação (histórica e social) entre o trabalho e a educação. Fato evidenciado no seguinte enunciado: aproximar o mundo do trabalho do universo da Educação. Dessa forma, 
percebeu-se que o uso do verbo aproximar delimita essa separação - só se pode aproximar-se de algo que está distante -, a partir disso levantou-se o seguinte questionamento: que condições de produção atuam no discurso do PPC para separá-los? Fez-se a mesma pergunta que Pêcheux (1999, p. 53): que "implícitos estão aí, onde residem?".

A memória discursiva é fator decisivo que influencia as condições de produção do discurso e fazem com que esse efeito de sentido (separação educação e trabalho) seja materializado. Sobre o conceito de condições de produção, Orlandi (1999, p. 30) diz que:

Elas compreendem fundamentalmente os sujeitos e a situação. Também a memória faz parte da produção do discurso ... Podemos considerar as condições de produção em sentido estrito e temos as circunstâncias de enunciação: é o contexto imediato. $\mathrm{E}$ se as considerarmos em sentido amplo, as condições de produção incluem o contexto sócio-histórico, ideológico.

Sendo assim, com base nos estudos da autora, todos os efeitos de sentido são tomados por conta das influências históricas, sociais e ideológicas e materializados em determinado contexto imediato: o IFTO, o curso do PRONATEC, os sujeitos que estão inseridos no processo, os discursos no PPC, todos estão ligados numa mesma teia e influenciados por memórias discursivas e interdiscursos.

Várias são as marcas que rompem o discurso e reforçam a separação entre os enunciados, mundo que se refere ao trabalho e universo, à educação. Essas marcas remetem à conclusão de que essas duas concepções teóricas estão muito distantes e precisam aproximar-se por meio do PRONATEC.

Em outra perspectiva, a forma de escrever trabalho com inicial minúscula e Educação com inicial maiúscula reforçam suas diferenças e grau de importância, pois, para dar ênfase à determinada palavra utiliza-se a letra maiúscula para criar esse limite. Estes deslizes estabelecem explicitamente que a educação, neste caso, possui um papel de maior importância em relação ao trabalho, realidade que retoma aspectos históricos e sociais históricos debatidos neste trabalho. Deste modo, infere-se que essas marcas discursivas evocam uma questão debatida neste trabalho: a dualidade educacional.

Essa concepção possui raízes profundas e reforça a divisão entre educação e trabalho que aparece no discurso. Suas bases retomam os processos históricos das primeiras sociedades, sendo representada nas seguintes modalidades de educação: de um lado, os dirigentes de Estado e chefes militares e suas famílias, 
que recebiam formação com base numa educação ampla, voltada para a cultura, ciência e artes. Na outra parte, os sujeitos responsáveis pelas atividades cotidianas e de manutenção das cidades recebiam uma educação para a prática, de caráter técnico, com baixo ensinamento teórico, a escola foi de fundamental importância na propagação desse processo (Saviani, 2007).

Com o processo contínuo de aprimoramento da indústria e do comércio, as relações de trabalho e educação foram modificadas de maneira significativa; a incorporação de tecnologia nos processos industriais e a necessidade de trabalhadores especializados e capacitados para atender as novas exigências do mercado motivaram a criação de novas estratégias para incluir ao mesmo tempo excluindo o trabalhador nesses padrões. Para isso, a formação técnica ganhou força como instrumento de capacitação e oportunidade de mudanças do padrão de vida dos trabalhadores (Kuenzer, 2007).

No Brasil, esse processo culminou na criação de políticas públicas que fizeram com que surgissem as instituições de ensino técnico, a exemplo do SENAI e o sistema $\mathrm{S}$ que até hoje possuem grande importância na formação dos trabalhadores, ao mesmo tempo se investe em escolas que prepara(va)m as elites com modelo de ensino propedêutico com vistas à universidade. Essa dinâmica percorre todo o processo histórico do país e várias políticas públicas foram instituídas visando à formação do trabalhador, e todas trouxeram em suas concepções ideológicas a diferenciação ao acesso à educação.

$\mathrm{O}$ aparecimento da marca discursiva, a consolidação de uma política pública, reforça que outros passos já tenham sido dados para fundamentar a criação dessa política. De certo modo, o PRONATEC faz parte de uma série de iniciativas que foram tomadas por vários governos, com ênfase na formação para o mercado, que deram continuidade no governo do Presidente Luiz Inácio Lula da Silva desde 2008, por meio da expansão da rede Federal no país, com intuito de ampliar o acesso ao ensino técnico, principalmente nas localidades mais distantes dos grandes centros, cita-se, por exemplo, a região Norte. Para isso o PRONATEC seria a iniciativa que concretizaria todo esse projeto, como reforça o texto do IFTO (2013, p. 5): O Programa Nacional de Acesso ao
Ensino Técnico e Emprego
(Pronatec), compreende a mais
ambiciosa e compreensiva reforma já
realizada na Educação Profissional e
Tecnológica (EPT) brasileira. Com a
meta de oferecer 8 milhões de vagas
a estudantes, trabalhadores diversos... 
De forma complementar a essa afirmativa, - outro efeito de sentido evocado no discurso - existe a presença de características que elevam a atuação do programa para além de seus objetivos, ao afirmar que representa, entretanto, mais do que, o cumprimento de uma obrigação formal. $\mathrm{O}$ aparecimento do termo comparativo mais do que evoca uma questão dialética. Como se esse novo programa de formação técnica fosse além das suas premissas básicas de formação do trabalhador, isto é, como se o PRONATEC (antítese) surgisse para consolidar e superar os demais modelos (tese) que antes tinham características meramente formais, que não se preocupavam com a inserção do sujeito na sociedade e a partir dele (PRONATEC), se criasse um novo modelo de ensino profissional (síntese). Este criaria um trabalhador totalmente responsável pelo desenvolvimento da região e que entende seu papel numa sociedade democrática e cidadã, realidade que o sujeito não formado ainda não está totalmente inserido.

\section{Considerações finais}

Ao final deste artigo pode-se entender é que o aprimoramento tecnológico industrial e o advento dos novos ordenamentos capitalistas influenciaram diretamente transformação e precarização das relações trabalhistas. A partir disto, aprofundou-se a proletarização do trabalho e a divisão entre o trabalho manual e o intelectual, remetendo ao velho e pertinente problema da dualidade educacional, questão não superada pelo regime de produção flexível defendido pelo mercado capitalista. Ademais, essa dinâmica interfere de forma significativa na formulação das políticas educacionais no país, fazendo com que se mantenham constantes investimentos em cursos aligeirados de formação técnica, a exemplo do PRONATEC.

Tais cursos beneficiam a rede privada de educação, com intuito de moldar o trabalhador para atender às necessidades do mercado, mantendo-se barreiras históricas que dificultam a sua inserção em ambientes educacionais mais complexos. Esta realidade aparece discursivamente nos enunciados analisados, que deixam escapar o grande influenciador da criação do PRONATEC, ou seja, a necessidade de atender ao capitalismo.

Outra questão relevante que se pode identificar a partir da análise do PPC se dá pela subordinação da ideia de cidadania ao cidadão produtivo, ou seja, aquele competente, habilidoso e conhecedor das técnicas administrativas exigidas pelo mercado. Esta noção, aparentemente está 
ligada a memórias históricas, que relacionam a qualificação como condicionante para a inserção produtiva do sujeito na dinâmica de consumo, social e política, neste caso, o camponês assentado na cidade de Araguatins.

Ao final desta pesquisa, pode-se afirmar que o PRONATEC possui uma significativa influência tecnicista, trazendo em seu contexto histórico as marcas de políticas anteriores, que serviram para atender as demandas do mercado. Contudo, essa iniciativa também demonstra em suas contradições que estão atualizadas as novas organizações de educação e trabalho, ou seja, o mundo atual é complexo e a inserção do camponês neste panorama se faz necessário, porém, nunca desvinculando suas raízes ideológicas de luta e confronto contra o capital.

\section{Referências}

Achard, P., et al. (1999). Memória e produção discursiva do sentido. In Achard, P., et al. (Orgs.). Papel da memória (pp. 11-17). Campinas: Pontes.

Lei n. 11.513, de 26 de outubro de 2011. (2011, 26 de outubro). Institui o Programa Nacional de Acesso ao Ensino Técnico e Emprego (Pronatec) e dá outras providências. Diário Oficial da União, seção 1 .

Cartilha PRONATEC CAMPO. (2011). Recuperado de http://www.mda.gov.br/sitemda/sites/sitem
da/files/user_img_23/cartilha\%20PRONA TEC_baixa.pdf.

Araújo, R. M. L. (2002). A reforma da educação profissional sob a ótica da noção de competências. In Anais da Reunião Anual da Anped-Associação Nacional de Pesquisa em Educação, 28(3), 1-18. Recuperado de: http://www.bts.senac.br/index.php/bts/artic le/view/532.

Araújo, R. M. L. (2004). As referências da pedagogia das competências. Revista Perspectiva, 22(2), 497-524.

Castioni, R. (2013). Planos, Projetos e Programas de Educação Profissional: agora é a vez do PRONATEC. Revista Sociais $e$ Humanas, 26(1), 25-42.

Chiavenato, I. (2010). Gestão de Pessoas. Rio de Janeiro: Campus.

Silva, J. A. (2014). Basta qualificar? O PRONATEC como estratégia de inclusão produtiva do plano Brasil Sem Miséria (Tese de Doutorado). Universidade Católica do Rio Grande do Sul, Rio Grande do Sul.

Fernandes, B. M., \& Molina, M. C. (2004). O campo da educação do campo. In Molina, M. C., \& Jesus, S. M. S. (Orgs.). Contribuições para a construção de um projeto de Educação do Campo (pp. 3252). Brasília: Ministério do Desenvolvimento Agrário.

Fleury, A., \& Fleury, M. (2004). Estratégias empresariais e formação de competências: um quebra cabeça caleidoscópico da indústria brasileira. São Paulo: Atlas.

Frigotto, G., \& Ciavatta, M. (2006). Educar o trabalhador cidadão produtivo ou ser humano emancipado? In Frigotto, G., \& Ciavatta, M. (Orgs.). Formação do 
cidadão produtivo: a cultura de mercado no ensino médio técnico (pp. 55-70). Brasília: Inep/MEC.

Gil, A. C. (2001). Gestão de Pessoas: Enfoque nos papéis profissionais. São Paulo: Atlas.

Harvey, D. A. (1992). Condição pósmoderna. São Paulo: Loyola.

Harvey, D. A. (2008). O Neoliberalismo: história e implicações. São Paulo: Loyola.

IFTO. Instituto Federal de Educação, Ciência e Tecnologia do Tocantins. (2013). PDI - Plano de Desenvolvimento Institucional 2015-2019. Recuperado de http://apps.ifto.edu.br/pdi/.

IFTO. Instituto Federal de Educação, Ciência e Tecnologia do Tocantins. (2013). Projeto Pedagógico de Curso Auxiliar Técnico em Agropecuária. Araguatins.

Kuenzer, A. Z. (2018). Competência como práxis: os dilemas da relação entre teoria e prática na educação dos trabalhadores. Boletim Técnico do SENAC, 29(1), 16-27. Recuperado de: http://bts.senac.br/index.php/bts/article/vie w/526

Kuenzer, A. Z. (2007). Da dualidade assumida à dualidade negada: o discurso da flexibilização justifica a inclusão excludente. Revista Educação e Sociedade, 28(100), 1153-1178. https://doi.org/10.1590/S0101$\underline{73302007000300024}$

Lima, M. (2012). Problemas da Educação Profissional do Governo Dilma: PRONATEC, PNE e DCNEMs. Revista Trabalho \& Educação, 21(2), 73-91. https://doi.org/10.17648/2238-037Xtrabedu-v28n3

Nascimento, M. L. O. (2016). O PRONATEC no âmbito das políticas públicas de educação profissional: da dualidade estrutural à mercantilização da qualificação profissional. (Dissertação de Mestrado). Universidade Federal do Piauí, Teresina. Recuperado de http://repositorio.ufpi.br/xmlui/handle/123 $\underline{456789 / 290 .}$.

Ohno, T. O. (1997). Sistema Toyota de Produção: além da produção em larga escala. Porto Alegre: Artes Médicas.

Orlandi, E. P. (1999). Análise de discurso: princípios e procedimentos. Campinas: Pontes.

Pêcheux, M. (1999). Papel da memória. In Achard, P. (Org.). Papel da memória (pp. 49-57). Campinas: Pontes.

Peinado, J., \& Graeml, A. R. (2007). Administração da produção. Curitiba.

Ribeiro, J. (2014). Pronatec diante da inclusão excludente e da privatização da formação. Revista Textual, 2(19), 16-21.

Saviani, D. (2007). Trabalho e educação: fundamentos ontológicos e históricos. Revista Brasileira de Educação, 12(34), 152-165. https://doi.org/10.1590/S141324782007000100012

Scottini, A. (1998). Dicionário escolar da língua portuguesa. Blumenau: Edições Todo Livro.

Tocantins. (2013). PRONATEC Tocantins sem miséria. Palmas: Secretaria do Trabalho e da Assistência Social.

\footnotetext{
i Título da dissertação de Mestrado defendida no ano de 2017, para obtenção de Mestre em Dinâmicas Territoriais e Sociedade da Amazônia, pela Universidade Federal do Sul e Sudeste do Pará (UNIFESSPA).

ii A autora entende por dualidade educacional, como o tratamento educacional diferenciado entre as classes abastadas e as pobres. O último recebe
} 
uma educação fragmentada e técnica voltada para o trabalho e a outra uma educação ampla e complexa, voltada para cargos e atividades de liderança.

iii Os referidos autores corroboram com a ideia defendida por Harvey (2008), que trata o Neoliberalismo como uma teoria econômica sedutora que nasceu no pós-guerra e enraizou-se nas diversas economias mundiais. Com um discurso inovador, porém contraditório, pois esconde em sua roupagem um viés ideológico conservador que apoia o autoritarismo de neoconservadores, nessa estratégia se reforça um mercado livre e a ação de um Estado coercitivo aliado aos interesses capitalistas. Essa base teórica possui como expoentes as obras de Frederick Von Hayek e Milton Friedman.

\author{
Informações do artigo / Article Information \\ Recebido em : 08/10/2018 \\ Aprovado em: 22/03/2019 \\ Publicado em: 29/02/2020 \\ Received on October 08th, 2018 \\ Accepted on March 22th, 2019 \\ Published on February, 29th, 2020
}

Contribuições no artigo: $O$ autor foi o responsável por todas as etapas e resultados da pesquisa, a saber: elaboração, análise e interpretação dos dados; escrita e revisão do conteúdo do manuscrito e; aprovação da versão final publicada.

Author Contributions: The author was responsible for the designing, delineating, analyzing and interpreting the data, production of the manuscript, critical revision of the content and approval of the final version published.

Conflitos de interesse: $O$ autor declarou não haver nenhum conflito de interesse referente a este artigo.

Conflict of Interest: None reported.

Orcid

Jorlan Lima Oliveira

(iD) http://orcid.org/0000-0002-4489-3934

Como citar este artigo / How to cite this article

APA

Oliveira, J. L. (2020). As memórias discursivas que emergem do discurso do Projeto Pedagógico de um curso técnico vinculado ao Pronatec Campo no IFTO, Campus Araguatins-TO. Rev. Bras. Educ. Camp., 5, e6018. http://dx.doi.org/10.20873/uft.rbec.e6018

ABNT

OLIVEIRA, J. L. As memórias discursivas que emergem do discurso do Projeto Pedagógico de um curso técnico vinculado ao Pronatec Campo no IFTO, Campus Araguatins-TO. Rev. Bras. Educ. Camp., Tocantinópolis, e6018, 2020. 